\title{
Web-based Case Studies for Continuous Professional Development via the ViCoCITY Case Study Support Tool
}

\author{
James A. Redmond, Audrey Stenson and Alan Mullally \\ Department of Computer Science, Trinity College, Dublin 2, Ireland \\ (redmond, audrey.stenson, alan.mullally)@cs.tcd.ie
}

\begin{abstract}
Web-based case studies offer some significant advantages over the traditional paper-based ones. The results from three uses of a Web-supported case study tool giving advantages and disadvantages are discussed from the viewpoints of student, lecturer and administrator with some discussion as to potential future improvements.
\end{abstract}

Key words: Case Study, Web-based support tool, e-Learning, Web-based teaching, Distance learning, face to face learning

\section{Introduction}

Trinity College has a long tradition of lifelong learning and continuous professional development. In particular, the teaching of Information Systems Management and Information Technology has been actively pursued by the School of Computer Science and Statistics for nearly forty years. Experience in the area led to the development and use of many different formats for presenting the various programmes involved. In particular, the use of case study methods, problem based-learning, simulation exercises and other active learning approaches became key to course and programme delivery. Many of these programmes were parttime programmes with students in employment and seeking up-skilling and development.

A characteristic of these programmes was a close relationship with employers and constant dialogue regarding their educational and training needs. As a consequence of this, there was in addition to the usual pressure to update, adapt and expand curricula, a need to have graduates contribute more effectively, and sooner, to their organisation after graduation. There was also the need to make postgraduates more competent and professional in their approach to work and the workplace. A clear emphasis was needed on the soft skills as opposed to the technical skills. Ideally, for professional students on a continuous, professional development (CPD) course, they should graduate with a real sense of the workplace and the context within which they will operate [1].

Academic faculty associated with these programmes have had considerable industry experience both at technologist and managerial levels. In addition, some had a background in e-Learning methods and technology. ViCoCITY evolved from this mixed background and is an effort to achieve a significant improvement in the way certain professional subjects are taught.

\section{Professional Practice}

The characteristics of the knowledge-based societies of today are an increasing demand for professional specialists and managers in an environment of constantly increasing business competition; high expectations of quality and service from the customers of the professions; unremitting change as a factor in the professions and business in a climate of the regular emergence of powerful new digital technologies.

These characteristics give rise to a growing and changing body of knowledge on an increasingly complex subject matter. They also give rise to a demand for more knowledgeable and skilled graduates, both in technical and managerial terms. There is a perceived requirement to make graduates productive at an earlier 
stage of their career, and to maintain and improve productivity over the whole of their career [2]. Consequently, there is a need to put more emphasis on acquiring and improving professional practice.

The typical undergraduate degree for a professional discipline usually concentrates on three distinct aspects of education and development of the individual:

- higher level thinking skills

- the understanding of the underpinning theoretical body of knowledge and models for that discipline

- the application of the theory to near 'real-world' problem situations and a reasonable sense of the 'professional practice' involved in addressing them.

'Professional Practice' usually involves:

- Improving relatively unstructured and complex problem situations

- Many of these situations have no 'right' answer so only balanced outcomes and decisions arise

- Rapid evaluation of complex situations as an everyday experience

- The need to take decisions under time, cost and other resource pressures

- Constant need to make judgements and assessments in the absence of detailed or complete facts

- Awareness and understanding of the social dimension within which business and professions actually function

- Facility to handle all aspects of communications and interpersonal skills: written, verbal and presentational

- Ability to think both tactically and strategically

- Understanding of group dynamics including teams, meetings etc.

The academic challenge is to provide a sense of 'real-world' professional practice which addresses the nature of a 'professional's' work. The traditional academic solution to this is the employment of a variety of active learning and experiential formats and coursework assignments e.g. Case Studies, Problem-based learning situations, Simulations, Role plays, Work experience, Projects, Team Projects etc. Games, serious and otherwise, have been used in management learning for decades [3].

A proposed new solution is the ViCoCITY Simulation Centre which was developed with the intention of assisting lecturers to simulate a real world environment. It consists of a set of virtual companies designed to transform coursework and improve the student's sense of 'Professional Practice'.

\section{The ViCoCITY Web-based Case Study Simulation Centre}

The Vicocity web-based, case study, simulation centre supports web-based case study learning [4], [5]. ViCoCITY is a research and teaching initiative currently being developed and implemented at Trinity College Dublin. It is also in experimental use in the Oscail Distance Education programme at Dublin City University. The ultimate purpose of ViCoCITY is to improve the quality of educational and training outcomes for certain professionals e.g. Managers, Accountants, IS professionals, Lawyers etc. ViCoCITY is a new innovative concept and support centre designed to transform the nature and purpose of coursework assignments in the teaching of certain professional topics.

The ViCoCITY simulation centre was developed with the intention of assisting lecturers and instructors to simulate a 'real-world' environment for their coursework assignments and so improve their student's sense of understanding and familiarity with actual professional practice likely to be experienced in the real world. It takes the form of a 'City' of companies and institutions, each with their particular culture and identity. Each of these is populated by people, products, services, documents, systems etc. The underpinning rationale and hypothesis for the ViCoCITY initiative is that it should contribute to improving, deepening and expanding the knowledge and practical expertise of the student.

The concept has been influenced by the following authors and methods:

- Kolb [6] with his experiential learning: Problem Based Learning [7], Savin-Baden [8];

- the case based approach in professional higher education [9], the Andragogical Model of adult learning [10] and

- finally, by the development of online, distance learning in the last decade [11].

On the teaching front, lecturers design and implement their own coursework assignments and projects based on the set of simulated companies within ViCoCITY. The companies provide a 'real-world' context within which the student learns. Figure 1 and 2 show the home pages of the EIC brochure website and the Big 


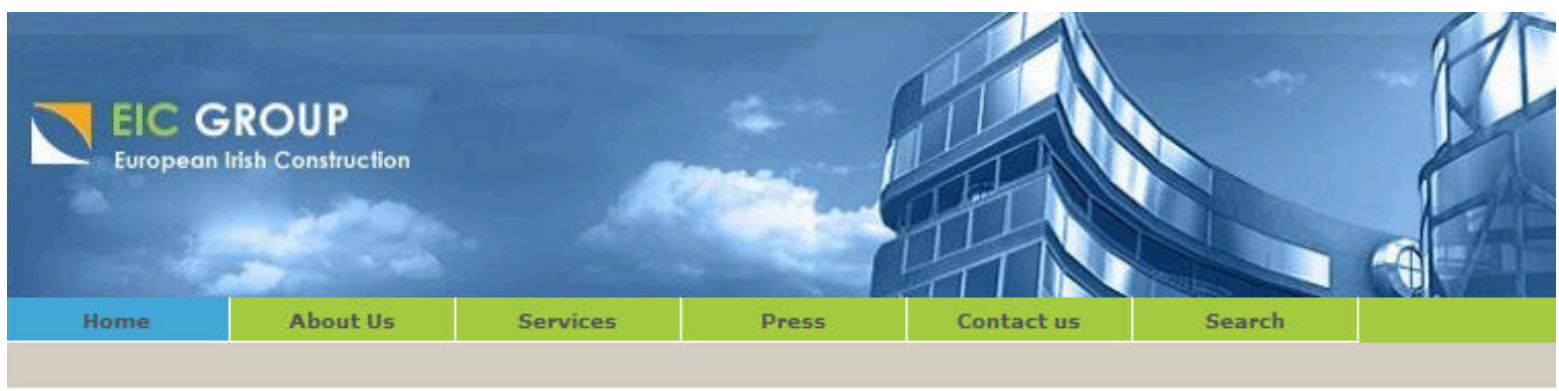

Based in ViCoCity, EIC Group is one of Europe's largest construction and property holding groups. We are regarded as one of the most innovative and progressive companies in the European building industry.

Over the years, EIC Group has built a solid reputation based on the principles of integrity, commitment, and innovation. Today, we provide a comprehensive range of services such as construction and restoration, facilities management, public and private partnership formation, and property development.

Our proven track record across a range of construction and property sectors includes the commercial, industrial, and residential sectors, including industries such as pharmaceutical, retail and financial services, hospitality, leisure and healthcare.

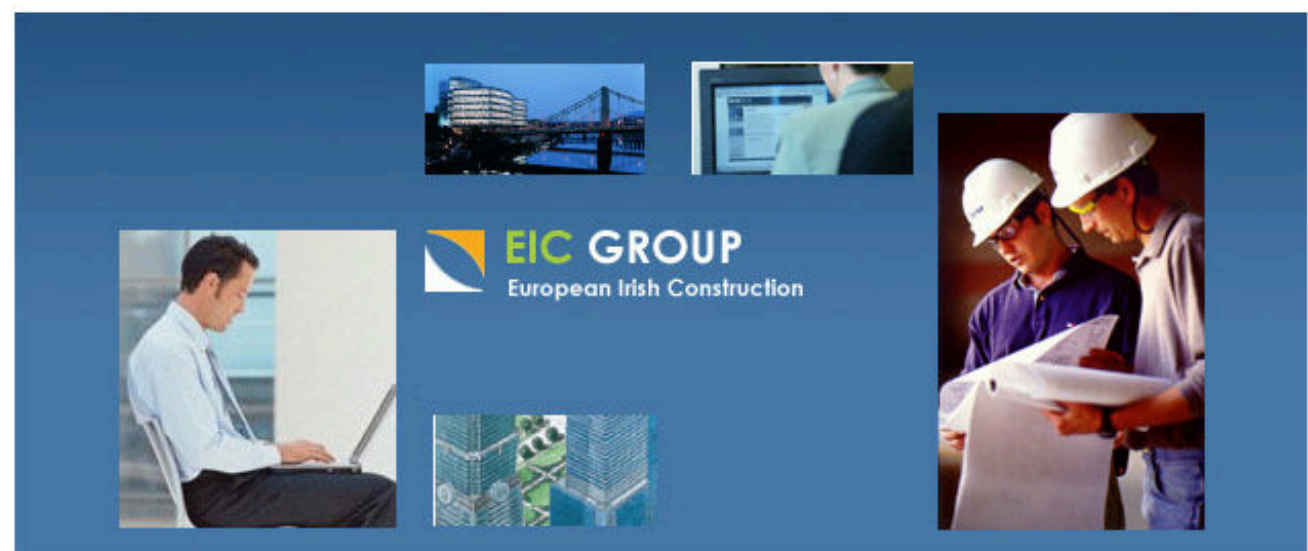

Fig. 1. M.Sc EIC Home Page

Ben brochure website. EIC and Big Ben are two of the simulated companies in the ViCoCITY Simulation Centre. Motivation is increased and the student is prepared to address the breadth of complex issues that are encountered within all disciplines. In particular the 'softer' skills can be addressed. The typical unstructured and complex problems without 'right answers' but yet requiring decisions can be simulated. Decisions are required under time and resource pressures just as in the real world. Strategic and tactical decisions and issues can be explored.

While the prototype system is being used on a number of courses within several institutions and has been very well received by academics and students alike, it has not been subjected to rigorous evaluation and research. This paper sets out to stimulate discussion among academics about the concepts involved and highlight the the scope of research topics and questions which can be derived from the initiative.

The ViCoCITY web-based case study/ course work tool has most, or all, of the following:

- A population of companies

- Each company has a number of descriptions of key personnel

- Summary accounts for each company

- General information about each company

- Ability to set assignments for a company

- Instructor ability to set a series of assignments over time, with time-released information

- All relevant documentation available online

- Ability for the Administrator to control many companies and assignments 


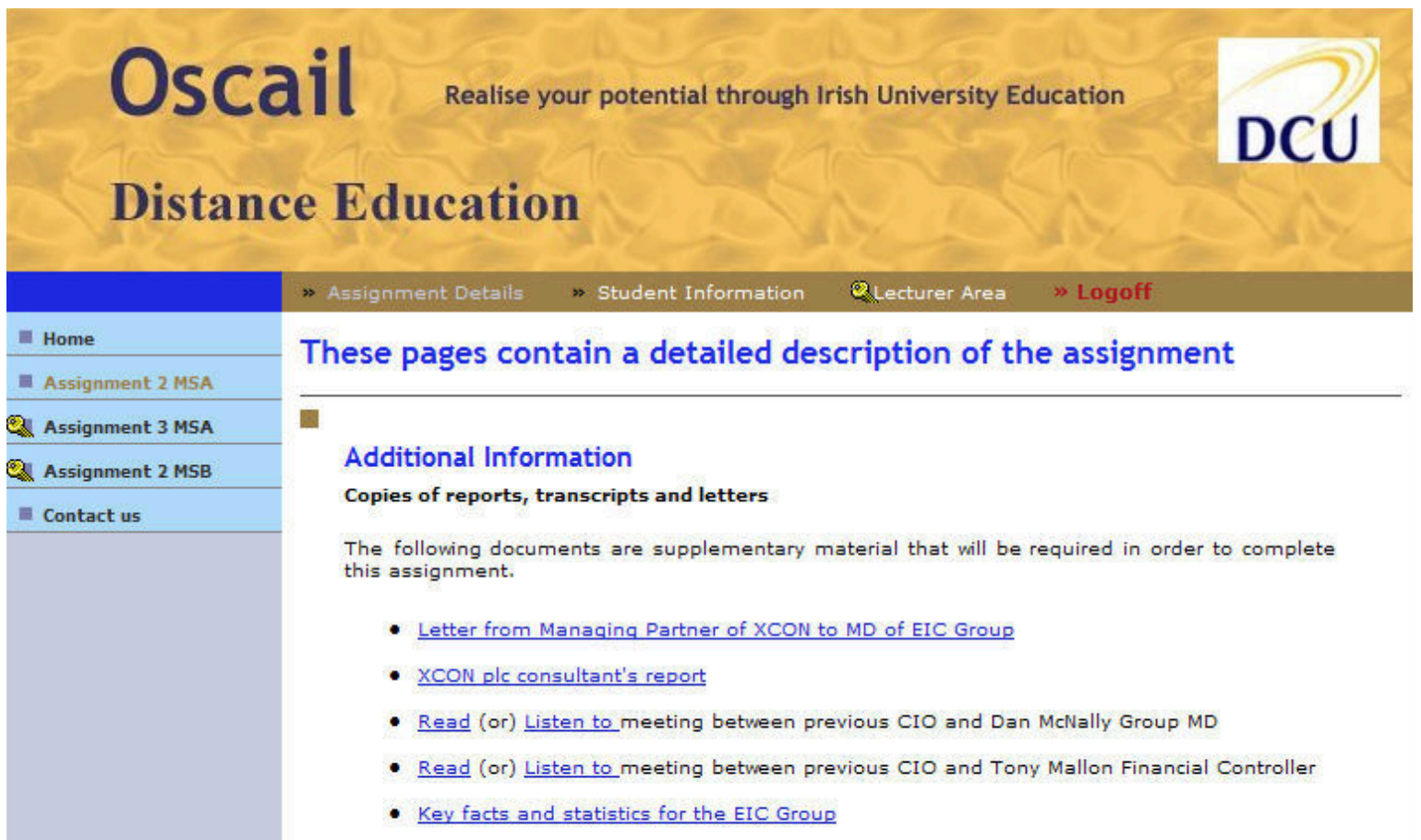

$\leq<$ BACK TO ASSIGNMENT DETAILS

Fig. 2. Big Ben Home Page

- The ability, for the administrator, to enrich any company

- Assignments can be used as templates for different courses

- Multi-platform

- Multimedia courseware with third-party authoring support

- Results of assignments can be recorded, edited and stored for later playback, instantly creating self-paced content for student review or for instructor training.

- Case studies can be used synchronously or asynchronously or both. A team can access an assignment together synchronously, while at other times team members can access the information asynchronously.

Within ViCoCITY virtually any type of assignment or coursework can be set:

- Short coursework assignment

- Individual or group project

- Problem based learning situation assignment

- Case study assignment

- Essay

- Management report or analysis

- Research type project

- Large scale Development Project

- Laboratory or field work type project

The lecturer's imagination is practically the only limiting factor to how ViCoCITY can be effectively used. Lecturers are free to exercise their own individual and particular approach, simply just using the ViCoCITY Simulation Centre for support.

The approach is non-prescriptive and respectful of the academic freedom and professional judgement of the lecturer on the one hand but provides a consistent, 'realworld' experience for the student.

ViCoCITY can support campus-based or distance-based courses.

- Any set of media or media mixes can be used or combined e.g. Paper, audio, video, podcasting, video conferencing, Messaging, Mobile telephony including 3G etc. 
- Traditional andragogical approaches e.g. Lectures, classes, seminars, workshops, laboratory sessions, case studies etc.

- More advanced andragogies e.g. problem based learning, active learning, simulations, role plays etc.

- Links to Learning Management Systems (LMSs) and Content Management Systems (CMSs) e.g WebCT, Moodle, Blackboard, Learnlinc, Breeze, Centra, iVocalise etc.

Depending upon the desired learning outcomes of the module or assignment, the academic can choose to use one or multiple organizations and companies in a single assignment, therefore maximizing the use of the virtual environment and simulating problem based learning for the students.

\section{Pilot Applications}

Three courses were used for testing the ViCoCITY concept.

\subsection{The TCD B.Sc. Programme in Information Systems}

Project Management is a subject that is most effectively based upon problem situation-based learning.

The overall purpose of using ViCoCITY for the project management module was to allow students to face real practical problems that exist in IT project management. While the theory of project management is pertinent, the area of actual application of this knowledge to problems was carried out through examples in class and paper based case studies. The purpose of this module was to explore real-life practical issues through both synchronous and asynchronous learning.

A sample screen for Assignment I for Project Management in the B.Sc. in Information systems is shown in Fig 3. This shows a relatively simple screen layout for an assignment in project management for second year undergraduates. Eight key items for completing the assignment have links on the page. 


\section{The University of Dublin | Trinity College}

\section{Ollscoil Atha Cliath I Colitiste na Trionoide}

\section{B.Sc. in Information Systems}

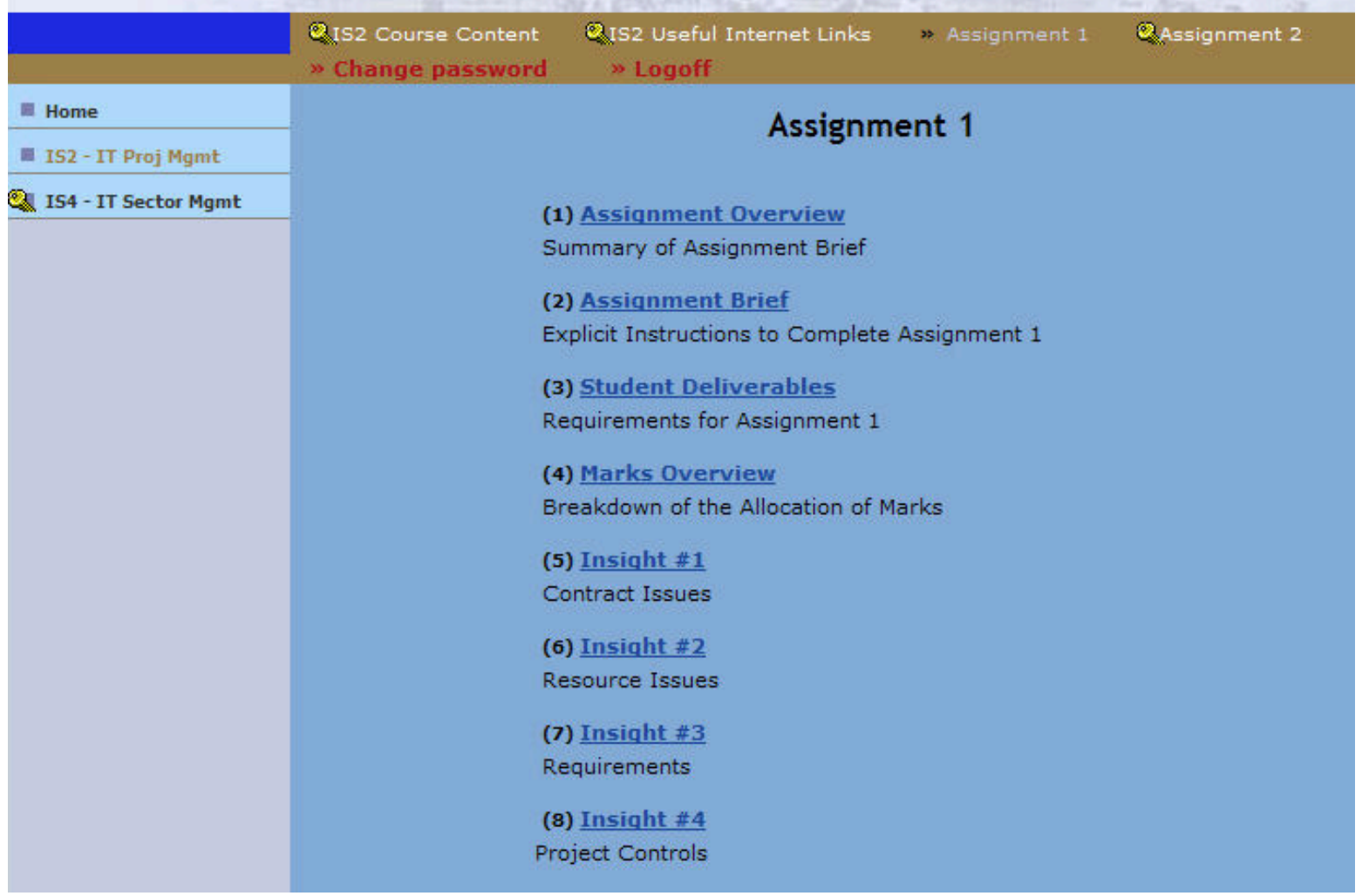

Fig 3. Assignment 1 - B.Sc in Information Systems

\subsection{The TCD M.Sc. Programme in Management Information Systems}

A sample case study scenario used in the first year of the two year M.Sc. Programme in Management Information Systems (about 35 students attended) is shown in Fig. 4.

The case study was essentially a replacement for a paper-based assignment used for a number of years. It still maintained a role-playing aspect by academics on a number of presentation nights. It proved popular with the students. A sample screen for Assignment I Brief for Project Management in the M.Sc. in Management Information Systems is shown in Fig 5. This screen shows details of a Board Presentation that must be done by a team to complete Assignment 1 for the M.Sc in M.I.S. This gives the explicit instructions for a team to give a Board presentation.

This is a more complex assignment screen than the previous ones, with a less linear layout of links. It also shows the other assignments to be completed in this academic year. 


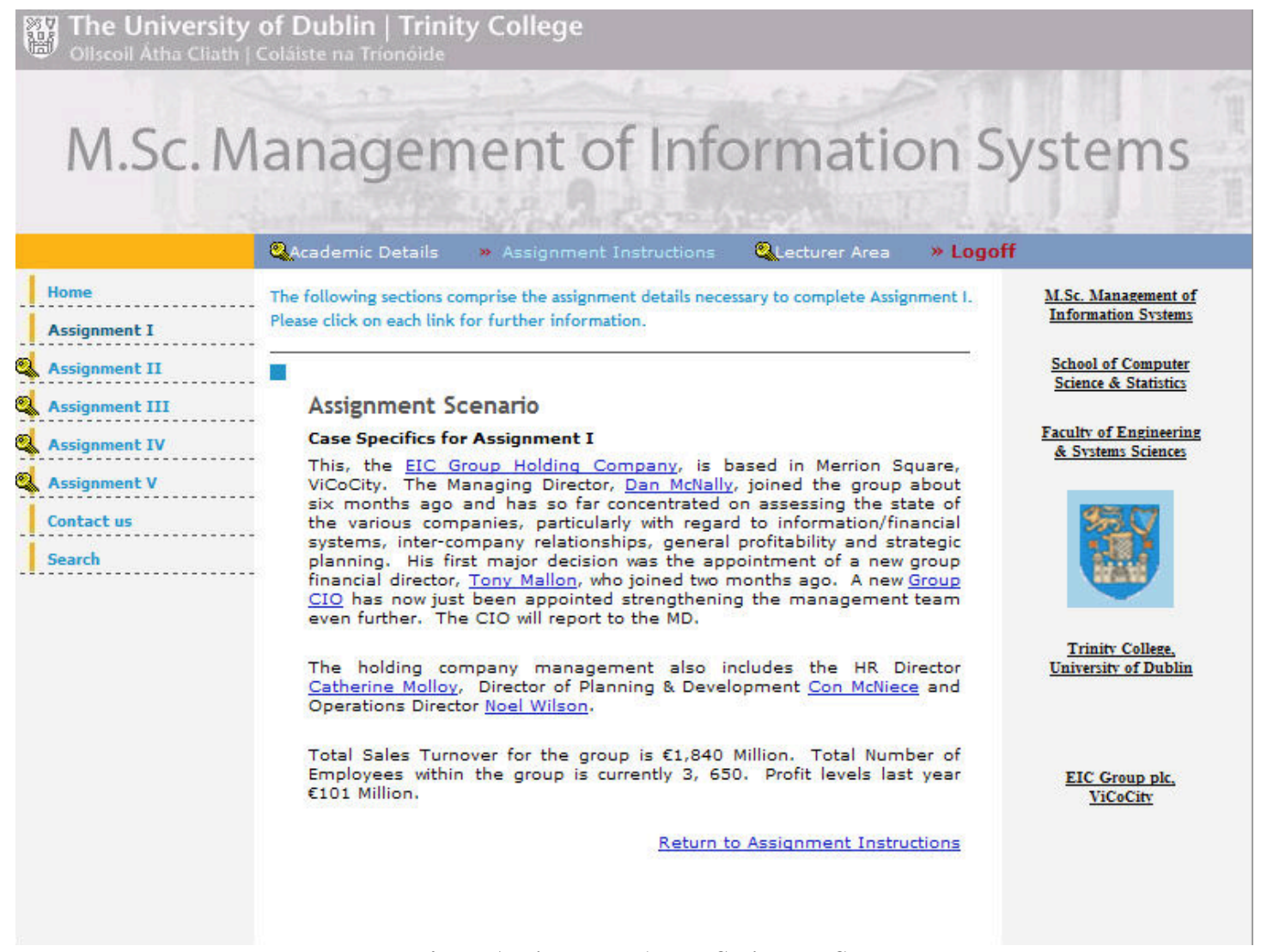

Fig 4. Assignment 1 - M.Sc in M.I.S.

\subsection{The DCU B.Sc. Programme in Information Technology}

This case study tool was used in the final year of the B.Sc. Programme in Information Technology in Dublin City University. Twenty two students attended this Distance Education course which had no face to face contact with the academic staff. The main differences with the TCD M.Sc. course was that there was no roleplaying feature. Other than this, most students were enthusiastic about the course but they also considered that the content needed to be enhanced.

\section{Three Perspectives}

The key features of Web-based Case Studies are looked at from three perspectives - those of Student, Lecturer and Administrator. These perspectives are informed by the results from the two TCD studies, and the study done in DCU.

\subsection{Student Perspective}




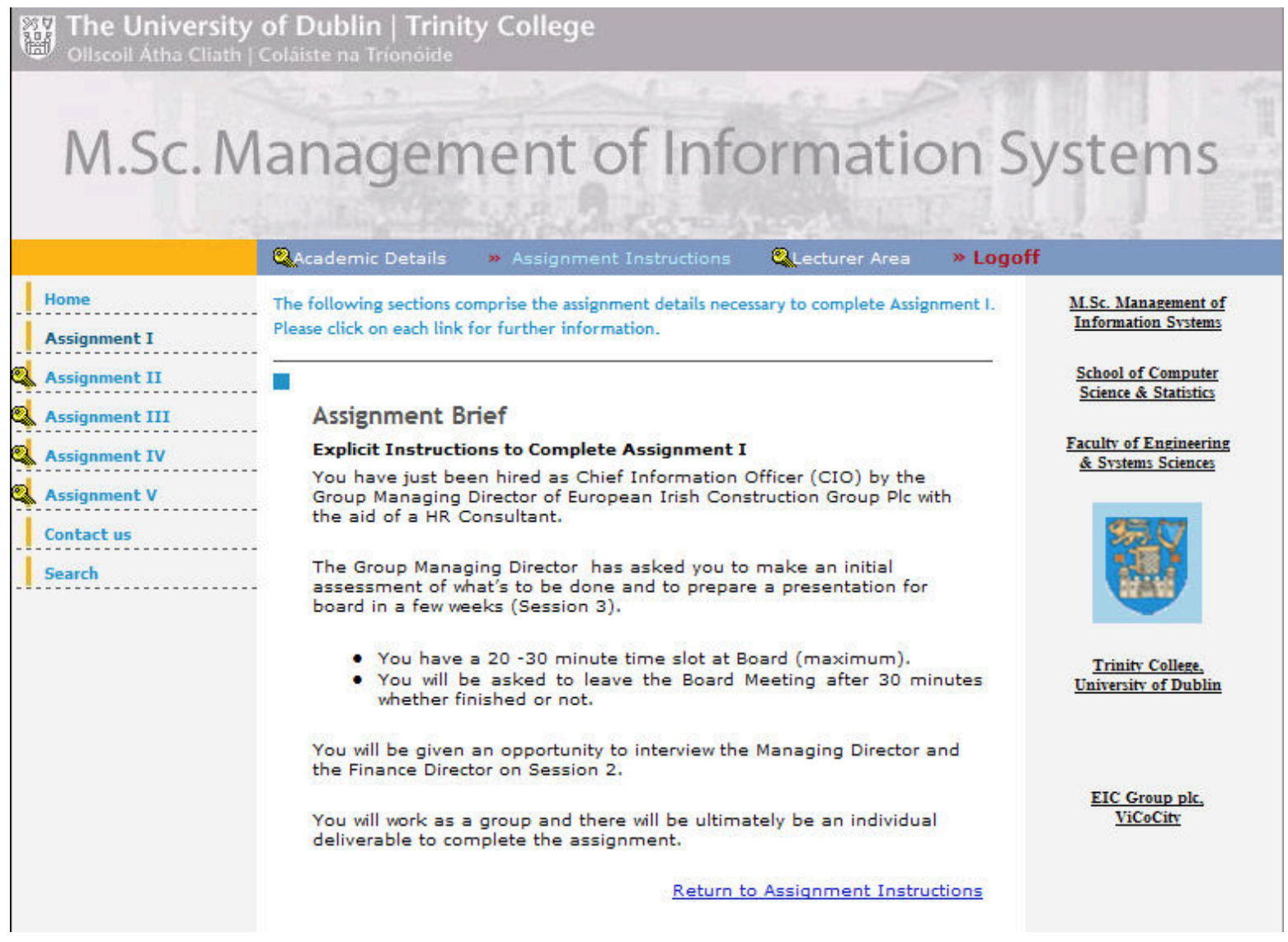

Fig 5. Assignment Brief - M.Sc in M.I.S.

\subsubsection{Simulated Real World Professional Practice}

Using ViCoCITY as part of the project management module (TCD B.Sc. in I.S.) with the undergraduate students had a significant disadvantage for the students. ViCoCITY was being used as part of one subject only and the remainder of the subjects were using other methods for course assignments. As a result the students were exposed to ViCoCITY for a single module rather than across the course. This raised some level of dissatisfaction among the students as they felt that a common platform or integrated projects across some or all subjects would have been more beneficial to their learning and understanding of the subject.

The feedback from the cohort of students consisted mainly of the fact that they would have preferred more information on the company websites and possibly more classroom work, in other words. a combination of synchronous and asynchronous learning.

Anecdotal evidence would suggest that the students preferred the combination of classroom and online delivery. The online delivery proved to be informative and the students could move at their own pace within the set timeframe of the assignment. The classroom environment proved dynamic insofar as teams of students had to resolve a problem quickly and effectively.

\subsubsection{Student Reaction}

The students also commented on the fact that they would have preferred more information on the 'companies' within ViCoCITY rather than just the brochure information that was available. The main written student 
reaction was to a small, one question evaluation done in DCU (twelve responses from twenty two B.Sc. in Information Technology students) as follows:

Question: The objective of ViCoCITY was to simulate a more real-life situation where you would have access to both internal and external information on the companies. Have you any comments on this form of assignment? Would you like this type of assignment used more widely?

\section{Responses:}

- This assignment I found very enjoyable as it simulated a real world experience in researching information to produce a report for the boss.

- Yes, I thought this was a good idea and was one of the most enjoyable assignments

- Yes. I thought it was a good experience.

- Challenging assignment but it took up time from other assignments because of the amount of additional effort and research that had to go into it.

- Would not like to have this for every subject but worked well for the Management Module

- I had no problem with this method

- Yes it was good

- I did think the virtual company was a good idea. This could be extended to other management modules.

- It worked very well

- The format as such was excellent. The task was not suitable for undergraduates

- Very interesting. Provided a clearer understanding of the role of the CIO in a company

- This was an interesting assignment. The format was clever and engaging. As someone who works in the industry I believe that this assignment had good parallels to some of the analytical skills needed in the real world.

\subsection{Lecturer Perspective}

The simulated 'real-life' view of ViCoCITY allows the lecturer to focus on competencies and professional development for the student.

ViCoCITY accentuates and illustrates theory covered in the classroom and allows the student to experiment with different approaches to the case studies in a 'safe' environment. Unlike the professional world, ViCoCITY is forgiving of mistakes and is designed specifically so that students can learn from successes and failures. This prevents them from making these mistakes in the real professional world and, more importantly, allows them to build on their successes.

The lecturer needs to plan and design the case studies, perhaps, at least 3 months in advance of using them in the classroom. While this may be an increase in workload at the outset, the workload will decrease as the case studies are completed.

The lecturer also needs to learn how to use the underlying tool, the WebSteps Admission Console, in order to make the changes required. The lecturer must take sole responsibility for this and ensure that they can make changes as quickly and efficiently as possible. The tool itself requires little prior knowledge of development or web design; however the lecturer must be computer literate and be able to use a package like MSWord. 
One conclusion from the project management application (TCD B.Sc in I.S.) would suggest that the students gain from a combination of synchronous/ asynchronous learning and traditional learning i.e. a combination of ViCoCITY and the classroom. The anecdotal response of the students would suggest that their understanding of the subject is best when illustrated by practical examples in the classroom environment.

The lecturers in the TCD M.Sc. in M.I.S. application found the web-based case studies were a distinct improvement on the paper-based ones from previous years. They had the advantage that the case studies could be updated and enhanced more easily. The students could also access the material asynchronously. Other media could also be added relatively easily e.g. audio. However, in general, they felt that the content in the companies needed to be enhanced.

The tutors in the DCU B.Sc. in Information Technology were enthusiastic about the use of ViCoCITY and made many suggestions for its improvement.

\subsection{Administrator Perspective}

There are quite a number of important factors pertinent to the administration of a web-based case study learning system as evidenced by the number of studies discussed above

Cost of planning and preparation: Websteps knowledge, gained through some basic level of training, lasting perhaps two hours, is required to get users set up. Lecturers need to be trained on this in order to maintain their own 'companies' and assignment webpages.

Software licensing costs: a modest annual fee for maintenance and hosting of the websites. All hosting is external with no internal costs. ViCoCITY must be set up in advance.

Training cost: Quite a small amount of training is necessary to run the exercise. Those who will lecture using the synchronous package need a small amount of training, perhaps two hours.

Setup: Little time and effort is necessary to access and run the software.

Staffing costs: Little expert technical support needs to be available.

Equipment provision and upgrading: Conventional PC equipment running on the Internet was used.

The undergraduate project management course (TCD B.Sc. in I.S.) utilized the use of two 'companies' in ViCoCITY that were specifically designed for the coursework. As a result of this small number of websites, the lecturer could also be the administrator. The Administration workload was significantly increased due to the training required on learning how to use the tool to create the websites, designing the case studies so that they were transferable to online learning, and designing the delivery of the coursework so that the students would benefit from this approach. A significant amount of time is required to prepare for the case studies and design the content, delivery and execution of the assignments. The synchronous and asynchronous learning need to be planned separately.

The TCD M.Sc. in M.I.S. application was the pilot course with which to experiment, and develop, ViCoCITY. Quite a number of people were participating and observing (approximately ten) so that the package was enhanced quickly and effectively.

The DCU B.Sc. in Information Technology was essentially a shadow site to the TCD site, to confirm that the experimental changes also worked well elsewhere. However a small evaluation was done on this Distance Education course as already discussed above.

\section{Advantages \& Disadvantages of ViCoCITY}

\subsection{Advantages for the Student}

ViCoCITY is a simulation centre that allows more intensive engagement with the topic, and according to anecdotal evidence, it is suggested that there is a deeper more permanent understanding of the field because the emphasis is on 'understanding' rather than 'memorising'. This can provide improved motivation to study the necessary material and to digest and engage with the formal lectures or other learning formats employed. The rich real-world situations and contexts can be provided using a variety of different and appropriate digital 
media with which deeper learning can be facilitated and enjoyed by the student. In addition to this, implemented as part of a programme over a short period of years, the student can acquire a better sense of organisational culture, management styles, personality types, inter-functional relationships, attitudes to change, institutional pressures etc. ViCoCITY provides a better chance for the student to address 'professional practice' type problems and situations e.g. decision making, problem solving, strategic thinking and collateral issues. This can, in turn, lead to a more effective employee in the workforce.

\subsection{Advantages for the Lecturer}

Learning to use ViCoCITY is simple and 'non-techie'. It takes about one hour to learn. The Lecturer retains her/his own approach and style of coursework. The readymade set of companies and organisations ease the lecturer workload by providing a choice of contexts within which an exercise or assignment can be situated. The advantages and benefits to the student result in a more satisfied, better motivated learner, and a better quality of teaching is a likely result.

The flexibility to apply any mix of delivery mode, media mix or andragogical model at will, and as appropriate to a given situation, is useful. Documentation is better organised and controlled e.g. version control for descriptions, financials, product details, services, reports, CVs etc. A template to assist in writing an assignment eases that task which is no more difficult than a conventional paper version.

The system is easily interfaced to learning management systems (LMS), content management systems (CMS) and other elearning products and services. The system is easy to use - it's of the same complexity as using Microsoft Word.

Quick changes to content and requirements can be easily made, if necessary. There is also the possibility of customising websites by individual difference such as cognitive style. Through the web, content is accessible world-wide. This suits students who need to travel for their work.

There is potential for evaluating different styles of presentation, perhaps to suit particular needs or individual differences. The tool supports teamwork and also less paper is used.

\subsection{Disadvantages for the Student, Lecturer and Administrator}

ViCoCITY is not reality, but just a model of reality. One of the current issues with ViCoCITY is the lack of features to allow the student to engage with the online environment. The information that is available on the 'companies' is brochure-like with basic knowledge. As a result, the details are the responsibility of the designer/lecturer to implement as part of the assignment structure, and delivery, to the class.

The ViCoCITY centre itself is not interactive and does not engage the student as a simulation centre in its own right. It requires the back-up of the classroom environment to provide appropriate feedback.

The question of evaluation is a current gap in ViCoCITY, although this is a major problem for most educational/ training tools. While anecdotally we can assume that the centre works sufficiently well, the statistics to enforce this statement are lacking.

For the moment, qualitative analysis has been carried out and anecdotal evidence would suggest that the students can see the benefits of the ViCoCITY approach. The quantitative method of evaluation would seem to fit better at assignment level as opposed to ViCoCITY level, but this method has yet to be defined and subsequently designed.

Specifically for the administrator, there is a small annual cost per annum of about $€ 400$ per website. There is a need to maintain sites (not particularly burdensome with the toolset provided) and a need to update the content regularly.

The interaction is not as good as with real, live role-playing "actors" (usually course lecturers). However, in general, real web interactivity can be costly in terms of funds, and resource availability such as fast broadband and webcams. Whether to go for interactivity is a judgement call with economic implications for the Administrator.

e-Learning is here to stay so an important question is how should we use it best. It should not be regarded as just a supposedly cheap way of delivering education and training

Another question with economic implications is how rich should the model be? For ViCoCITY an important 
question is how much detail is enough? This probably depends on the course purpose, content and economics.

\section{Discussion/ Conclusions}

The academic challenge is to provide a sense of a relatively 'real-world' professional practice in a 'safe', simulated and controlled virtual environment. ViCoCITY is a step towards meeting this challenge. The richness of the traditional learning environment is not compromised for the student, but is enhanced, and the delivery method for the lecturer is flexible.

ViCoCITY lacks the interactive dimension with regard to the online experience. Currently the case studies are 'flat' and are emphasized simply through the classroom experience where the students can engage in active discussion and feedback with their peers and the lecturer(s).

Anecdotal evidence would suggest that the ViCoCITY centre is the first step towards providing a 'professional practice' simulated environment for students. The comparison, so far, between the advantages of using paper-based and web-based case studies has been limited to qualitative analysis based upon interviews and discussions with academics and students exposed to the centre. Further quantitative evidence is required to investigate the question of the effectiveness of using web based case studies as opposed to using paper based techniques. To date, qualitative evidence from students, lecturers and administrators supports the hypothesis that ViCoCITY is an effective tool in the learning of professional practice.

Evaluation of ViCoCITY and its effectiveness for the student, lecturer and administrator is a difficult process. At present, there is a lack of information on evaluation of case based techniques and their effectiveness in a learning environment. Case studies are by nature open-ended and do not have one correct answer, so their evaluation can prove difficult and subjective.

Initial trials of the ViCoCITY concept have demonstrated considerable potential and have been generally well received. The next step is to extend the trials to other disciplines, institutions and topics. Systematic research is then needed on the lines outlined above in order to evaluate and hopefully enhance the process further. Although it is somewhat early to judge, there is a significant likelihood that the concept could have significant potential both within academia and business.

\section{The Future for ViCoCITY}

The ViCoCITY concept is a work in progress. It is in operation at two institutions currently and is planned for implementation at several more. It is being used on seven distinct courses. Upwards of a dozen coursework assignments are currently operating.

So far the reports are very encouraging, both from students and academics. However there are few real research results to support the anecdotal evidence as yet. There are many different questions and issues that need to be addressed.

Immediate issues that spring to mind include: How can the concept best be evaluated? Can it improve the quality of professional education? Is it more suitable to specific disciplines or topics? What are the economic, social and operational implications of using it? What are the advantages for the lecturer, student and institutional administrator? Is it more suitable to certain delivery methods? Is it best used with certain media? Which andragogical strategies does it best support? It is not fully clear what topics are really suitable for ViCoCITY other than topics that are usually covered in paper case studies.

Some other questions are:

- Does the approach improve student motivation, commitment and engagement?

- Is learning actually improved?

- Is 'professional practice' improved?

- Are graduates 'useful' at an earlier stage?

- What mix of media is best suited to any given situation?

- How suitable is the method for different modes of delivery e.g. Distance Education, Campus-based Education, Hybrid/Blended approaches etc.

Is it more suitable for particular types of learning or cognitive styles? 


\section{Acknowledgements}

We would like to thank George Morgan, Tony Niland, Noel Faughnan, Stuart McLoughlin, Barry Collins and Catherine O'Connor of TCD for their efforts and suggestions. We are also indebted to Séamus Fox, Mairéad McCarthy and Ursula Stapleton of Oscail, Dublin City University. We would like to thank staff and students of the Executive Master of Science Information Systems - Information Technology Management Program of Virginia Commonwealth University, USA for their useful feedback from a presentation of ViCoCITY, in particular, Maureen Carley and others.

\section{References}

1. Brennan, J. and Shah, T. (2003) Access to what? Opportunities in education and employment. In: Higher education and the lifecourse. Open University Press, Buckingham, UK, pp. 106-121. ISBN 0-335-21377-4 \& 978-0-335-21377-1

2. Brennan, J., Little, B., Connor, H., de Weert, E., Delve, S., Harris, J., Josselyn, B., Ratcliffe, N., and Scesa, A. (2006) Towards a strategy for workplace learning: Report to HEFCE by CHERI and KPMG. Higher Education Funding Council for England, Bristol, UK.

3. Ludlow, R. \& Wheeler, B, (1986) The use of Business Games in General Management Programmes, in Perspectives in Gaming and Simulation II Gaming and Simulation for Capability. Edited by Craig, D. and Martin, A. The proceedings of the 1985 conference of SAGSET, Society of Advancement of Games and Simulations in Education and Training, held at Heriot-Watt University, Edinburgh. 1986.

4. Mullally, A \& Redmond, J. (2007) A. An Academic Challenge: ViCoCITY - A Virtual City comprising web-based Company Simulations for Improving the Teaching of Professional Disciplines in Elsin XII Exploring Styles: Enhancing the Capacity to Learn? Proceedings of the 12th Annual Conference of the European Learning Styles Information Network 12-14th June 2007 Trinity College Dublin, Ireland pp. 102-107, ISBN: 978-80-903744-1-6.

5. Stenson, A. (2007) Websteps Workshop in Elsin XII Exploring Styles: Enhancing the Capacity to Learn? Proceedings of the 12th Annual Conference of the European Learning Styles Information Network 12-14th June 2007 Trinity College Dublin, Ireland pp. 234-241 ISBN: 978-80-903744-1-6.

6. Kolb, D.A. (1984) Experiential Learning - Experience as the source of learning and development Prentice Hall. 1984

7. Glascow, N.A. (1997) New Curriculum for New Times - A Guide to Student centred Problem Based Learning Neal A Glascow Cowin Press Inc 1997

8. Savin-Baden, M. (2003) Facilitating Problem Based Learning - Illuminating Perspectives, SRHE and Open University Press, McGraw-Hill Education, Philadelphia USA 2003 ISBN 0-335-21054-6

9. Crosling, G \& Webb, G. (2002) Supporting Student Learning - Case Studies Experience and Practice from Higher Education Edited by Glenda Crosling \& Graham Webb Kogan Page Ltd 2002

10. Knowles, M. S., Holton III, E. F and Swanson R. A. (2005) The Adult Learner, 6th Ed. California: Elsevier Butterworth Heinemann, 2005.

11. Wiita, E.L. \& Lee, C-Y (2005) Developing an Online Learning Style Instrument in Encylopedia of Distance Learning. Volume Two Idea Group Reference, Hershey, London, Melbourne, Singapore 2005. 